ISSN: 1980-055X

NOTA DE PESQUISA

\title{
EVENTOS EXTREMOS: ESTUDO DA CHUVA DE GRANIZO DE 21 DE ABRIL DE 2008 NA CIDADE DE MARINGÁ-PR
}

\author{
André Geraldo Berezuk ${ }^{38}$
}

\begin{abstract}
RESUMO
No dia 21 de abril de 2008 a cidade de Maringá foi atingida, muito provavelmente, pela mais intensa chuva de granizo dos seus 62 anos de existência. Em um período de oito minutos, caíram pedras de gelo do diâmetro de ovos de galinha. Aproximadamente mil casas da cidade foram atingidas, foram registradas aproximadamente 300 ocorrências de emergência, além dos muitos outros transtornos que eventos extremos dessa magnitude ocasionam. Depois da cidade ter decretado estado de emergência após a tempestade, vêm a indagação: estariam as cidades brasileiras preparadas para a ocorrência desses eventos climáticos?
\end{abstract}

Palavras-chave: Maringá, chuva de granizo, eventos extremos.

\begin{abstract}
In April $21^{\text {th }} 2008$ the city of Maringa was hit for probably the worst hail storm of its 62 years of existence. The hail storm lasted eight minutes, and the hails had a diameter as chicken eggs. At least a thousand houses were shot and three hundred emergency calls were reported. After the city has declared state of emergency because of the damages, we make a questioning: Brazilian cities were prepared for this kind of hazard?
\end{abstract}

Key-words: Maringa, hail storm, hazards.

\section{INTRODUÇÃO}

No feriado do dia de Tiradentes, em 2008, o norte do Paraná e o sul do Mato Grosso do Sul foram atingidos por área de fortes chuvas que ocasionaram fortes rajadas de vento e ocorrência de granizo. Maringá, cidade de

38Geógrafo, Professor do Curso de Geografia da Universidade Federal da Grande Dourados, Rodovia Dourados - Itahum, km 12 - 79.804-970 - Dourados/MS 
aproximadamente 350.000 habitantes, foi atingida por granizo, entre as 14:58h e 15:06 e entre as 15:55h até às 16:00h, especialmente no primeiro período citado, que os meteorologistas da Estação Climatológica Principal de Maringá classificaram como saraiva. Foram, naquela tarde, contados longos oito minutos de saraiva, com pedras de gelo que atingiam um diâmetro de até cinco centímetros.

As chuvas de granizo não são raras nos estados do sul brasileiro, em especial nos Estados do Rio Grande do Sul e de Santa Catarina. Entretanto, chama atenção o período de ocorrência de precipitação de granizo nesse evento, no total treze minutos, o que, aliado à intensidade e ao tamanho das pedras de gelo, foi constado como uma "eternidade" aos moradores maringaenses (vide fotos). Ocorreram também eventos de granizo em outras localidades do norte do Paraná, tais como: Apucarana (Distrito de São Domingos), Londrina (zona rural) Engenheiro Beltrão, Fênix, Quinta do Sol e Rolândia (cujas ruas chegaram a ter $50 \mathrm{~cm}$ de espessura de granizo). No Estado do Mato Grosso do Sul, foi registrado granizo em Fátima do Sul (com o famoso caso regional do gelo que demorou três meses para derreter em uma baixada na zona rural).
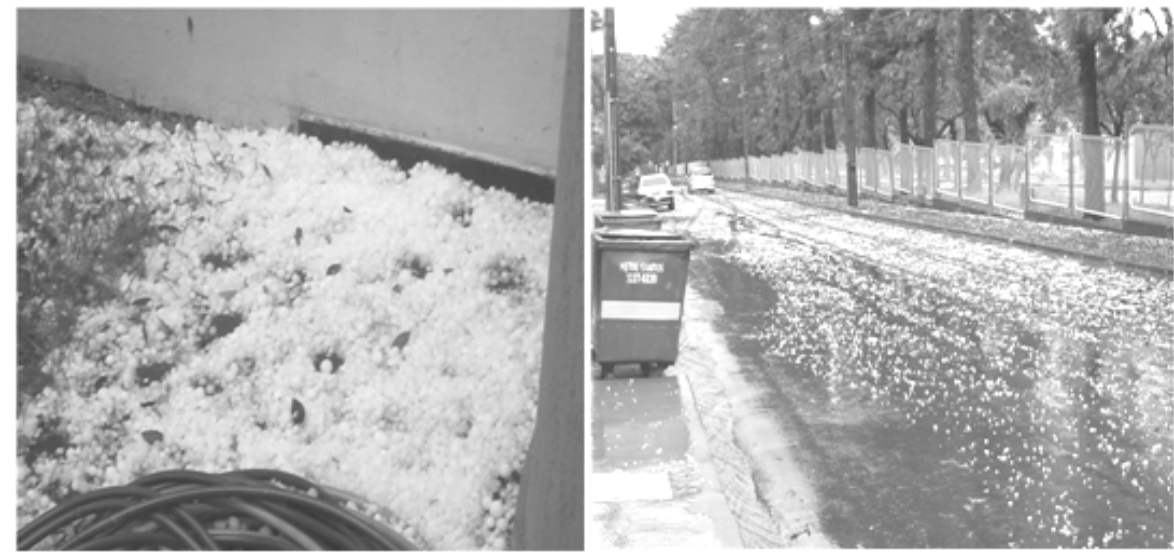

Figura 1 - Fotos do granizo do dia 21 de abril de 2008.

Tal como característico nos eventos climáticos extremos, sua duração significativa e sua intensidade causaram estragos em toda a cidade, com ênfase especial aos prejuízos relacionados às casas que possuíam telhas de amianto. Denota-se, portanto, uma das nuances características dos eventos de adversidades climáticas: o seu aspecto sócio-econômico, uma vez que as telhas de amianto são mais baratas que as novas telhas ecológicas, ou que as tradicionais e resistentes telhas de argila. Além disso, o grau de fragilidade das telhas de amianto aumenta ainda mais com a idade de utilização delas, sendo portanto, muito mais vulneráveis a eventos climáticos. Foram atingidas mil casas em toda a cidade aproximadamente, com a queda de muitas árvores e inúmeros casos de corte de energia.

\section{METODOLOGIA E INTERPRETAÇÃO DOS DADOS}

Para uma análise básica desse evento atmosférico, foram coletados dados de pressão atmosférica, temperatura em ar seco e úmido, umidade relativa, direção do vento, evapotranspiração, horas de insolação diária, volume de precipitação, nível de visibilidade, grau de nebulosidade e intensidade dos 154 
ventos do dia 21 de abril da Estação Climatológica Principal de Maringá, entre os dias 16 a 25 de abril (Tabela 1 ).

Tabela 1 - ECPM - Dados - Maringá entre os dias 16 a 25 de abril de 2008

\begin{tabular}{|c|c|c|c|c|c|c|c|c|c|}
\hline & \multicolumn{3}{|c|}{ Pressão Atm. (MB) } & \multicolumn{3}{|c|}{ Temperatura - Ar Seco } & \multicolumn{3}{|c|}{ Temperatura - Ar Umido } \\
\hline & $12 \mathrm{~h}$ & $18 \mathrm{~h}$ & $24 \mathrm{~h}$ & $12 \mathrm{~h}$ & $18 \mathrm{~h}$ & $24 \mathrm{~h}$ & $12 \mathrm{~h}$ & $18 \mathrm{~h}$ & $24 \mathrm{~h}$ \\
\hline $16 / 04$ & 955.5 & 954.7 & 955.4 & 18.0 & 21.2 & 19.8 & 17.4 & 20.0 & 19.6 \\
\hline $17 / 04$ & 956.8 & 954.3 & 955.8 & 21.6 & 27.1 & 21.0 & 20.0 & 22.3 & 19.3 \\
\hline $18 / 04$ & 956.0 & 953.0 & 954.6 & 22.4 & 27.4 & 22.1 & 18.8 & 21.8 & 19.9 \\
\hline $19 / 04$ & 953.5 & 953.4 & 951.9 & 19.1 & 23.2 & 19.0 & 17.9 & 20.4 & 18.4 \\
\hline $20 / 04$ & 953.0 & 951.0 & 951.2 & 20.2 & 25.5 & 21.4 & 19.2 & 20.8 & 19.2 \\
\hline $21 / 04$ & 953.0 & 950.0 & 951.8 & 21.2 & 24.0 & 18.4 & 19.7 & 21.3 & 17.6 \\
\hline $22 / 04$ & 953.1 & 950.6 & 950.6 & 20.6 & 21.0 & 21.1 & 18.6 & 18.4 & 19.0 \\
\hline $23 / 04$ & 952.3 & 949.5 & 949.8 & 20.7 & 26.4 & 21.6 & 19.1 & 18.3 & 17.9 \\
\hline $24 / 04$ & 951.0 & 948.8 & 949.5 & 20.8 & 26.1 & 21.4 & 18.4 & 18.6 & 17.0 \\
\hline \multirow[t]{3}{*}{$25 / 04$} & 951.0 & 948.4 & 949.8 & 20.3 & 26.0 & 21.2 & 17.3 & 17.8 & 17.0 \\
\hline & \multicolumn{3}{|c|}{ Vento (dir.) } & \multirow{2}{*}{$\begin{array}{l}\text { Evap. } \\
(\mathrm{mm})\end{array}$} & \multicolumn{3}{|c|}{ UR (\%) } & \multirow{2}{*}{\multicolumn{2}{|c|}{ Insolação (h) }} \\
\hline & $12 \mathrm{~h}$ & $18 \mathrm{~h}$ & $24 \mathrm{~h}$ & & $12 \mathrm{~h}$ & $18 \mathrm{~h}$ & $24 \mathrm{~h}$ & & \\
\hline $16 / 04$ & $E$ & $C$ & $C$ & 2.2 & 94 & 89 & 98 & \multicolumn{2}{|c|}{0.0} \\
\hline $17 / 04$ & $C$ & SW & SE & 0.4 & 86 & 65 & 84 & \multicolumn{2}{|c|}{8.2} \\
\hline $18 / 04$ & $\mathrm{NE}$ & $E$ & $\mathrm{~S}$ & 3.1 & 70 & 60 & 80 & \multicolumn{2}{|c|}{6.9} \\
\hline $19 / 04$ & SE & $E$ & $C$ & 3.3 & 88 & 76 & 94 & \multicolumn{2}{|c|}{2.5} \\
\hline $20 / 04$ & C & $\mathrm{N}$ & SW & 1.3 & 91 & 65 & 81 & \multicolumn{2}{|c|}{7.2} \\
\hline $21 / 04$ & NE & SW & C & 2.0 & 86 & 77 & 92 & \multicolumn{2}{|c|}{5.9} \\
\hline $22 / 04$ & $\mathrm{NE}$ & $\mathrm{NE}$ & C & 1.2 & 82 & 77 & 81 & \multicolumn{2}{|c|}{8.2} \\
\hline $23 / 04$ & C & SW & SW & 1.3 & 86 & 42 & 68 & \multicolumn{2}{|c|}{10.2} \\
\hline $24 / 04$ & $C$ & NW & $\mathrm{S}$ & 3.3 & 79 & 47 & 63 & \multicolumn{2}{|c|}{10.0} \\
\hline $25 / 04$ & SE & SE & $C$ & 3.9 & 74 & 42 & 65 & \multicolumn{2}{|c|}{10.5} \\
\hline & \multicolumn{3}{|c|}{ Precipitação (mm) } & Visi & ade ( & go) & Nebul & dade ( & mos) \\
\hline & $12 \mathrm{~h}$ & $18 \mathrm{~h}$ & $24 \mathrm{~h}$ & $12 \mathrm{~h}$ & $18 \mathrm{~h}$ & $24 \mathrm{~h}$ & $12 \mathrm{~h}$ & $18 \mathrm{~h}$ & $24 \mathrm{~h}$ \\
\hline $16 / 04$ & 2.8 & 3.0 & 0.6 & 6 & 6 & 6 & 10 & 10 & 10 \\
\hline $17 / 04$ & 0.0 & 0.0 & 0.0 & 6 & 6 & 7 & 7 & 7 & 0 \\
\hline $18 / 04$ & 0.0 & 0.0 & 0.0 & 7 & 7 & 7 & 9 & 8 & 10 \\
\hline $19 / 04$ & 3.5 & 0.0 & 0.8 & 7 & 6 & 6 & 10 & 10 & 10 \\
\hline $20 / 04$ & 0.0 & 0.0 & 0.0 & 6 & 7 & 7 & 10 & 3 & 6 \\
\hline $21 / 04$ & 0.0 & 18.8 & 12.0 & 7 & 6 & 6 & 9 & 10 & 6 \\
\hline $22 / 04$ & 0.0 & 12.2 & 0.0 & 6 & 6 & 7 & 1 & 8 & 2 \\
\hline $23 / 04$ & 0.0 & 0.0 & 0.0 & 7 & 7 & 7 & 0 & 1 & 0 \\
\hline $24 / 04$ & 0.0 & 0.0 & 0.0 & 6 & 7 & 7 & 0 & 1 & 0 \\
\hline $25 / 04$ & 0.0 & 0.0 & 0.0 & 6 & 6 & 7 & 0 & 4 & 2 \\
\hline bs: Hor & med & undo & $\mathrm{o} \mathrm{me}$ & no de & wi & & & & \\
\hline & & & & Dia 21/C & & & & & \\
\hline & & & & & $14: 58$ & $15: 06$ & & & \\
\hline & & & & & $15: 55$ & $16: 00$ & & & \\
\hline & & & & $15: 00$ & $5: 10 h$ & $0 \mathrm{~m} /$ & $22,0 \mathrm{~m} /$ & & \\
\hline & & & & & $20: 30$ & $21: 2$ & & & \\
\hline & & & $S, S$ & $14: 30$ & $15: 4 C$ & JW - 1 & $0-16:$ & & \\
\hline Rel & ggo & & $\mathrm{S}, \mathrm{S}$ & $14: 30$ & $15: 4 C$ & IW - 1 & 0h-16: & & \\
\hline Ventos & $21 / 04$ & & & & fão e & sidac & & & \\
\hline $7 \mathrm{~h}$ & NE1.0 & & $12 \mathrm{~h}$ & NE1.0 & & $17 \mathrm{~h}$ & SE1.0 & & \\
\hline $8 \mathrm{~h}$ & NE1.0 & & $13 \mathrm{~h}$ & $\mathrm{~N} 1.0$ & & $18 \mathrm{~h}$ & SE1.0 & & \\
\hline $9 \mathrm{~h}$ & NE1.0 & & $14 \mathrm{~h}$ & E1.0 & & $19 \mathrm{~h}$ & C & & \\
\hline $10 \mathrm{~h}$ & SE1.0 & & $15 \mathrm{~h}$ & $\begin{array}{c}\text { SW12. } \\
0\end{array}$ & & $20 \mathrm{~h}$ & $\mathrm{C}$ & $22 \mathrm{~h}$ & $\mathrm{C}$ \\
\hline $11 \mathrm{~h}$ & NE1.0 & & $16 \mathrm{~h}$ & S1.0 & & $21 \mathrm{~h}$ & C & $23 \mathrm{~h}$ & C \\
\hline
\end{tabular}


Para uma análise mais aprofundada da atuação dos mecanismos atmosféricos no decorrer do estudo de caso, foram utilizadas cartas sinóticas da Marinha do Brasil para a efetuação de uma correlação de análise com os dados coletados da ECPM, datadas as cartas com o mesmo segmento temporal (só não foi obtida a carta sinótica do dia 17 de abril) (Figuras 2 a 5).

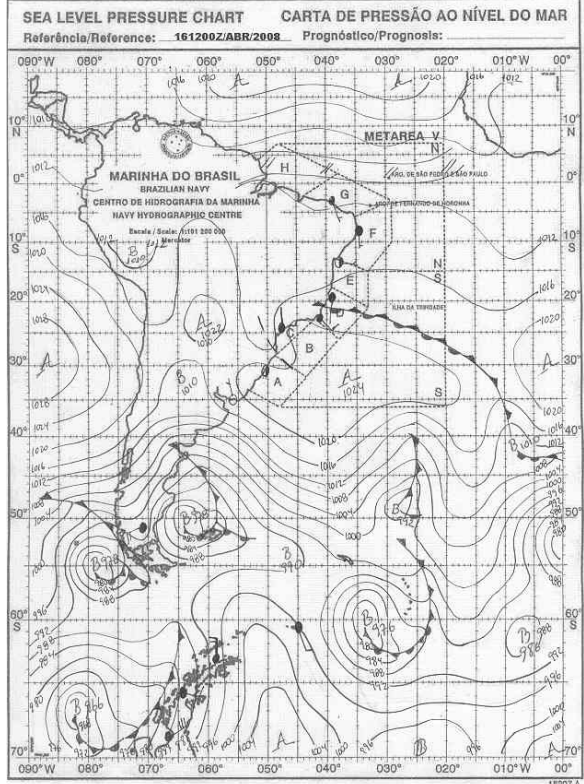

Figura 2 - Carta Sinótica do dia 16 de abril de 2008. - Fonte: Marinha do Brasil, Serviço Meteorológico Marinho

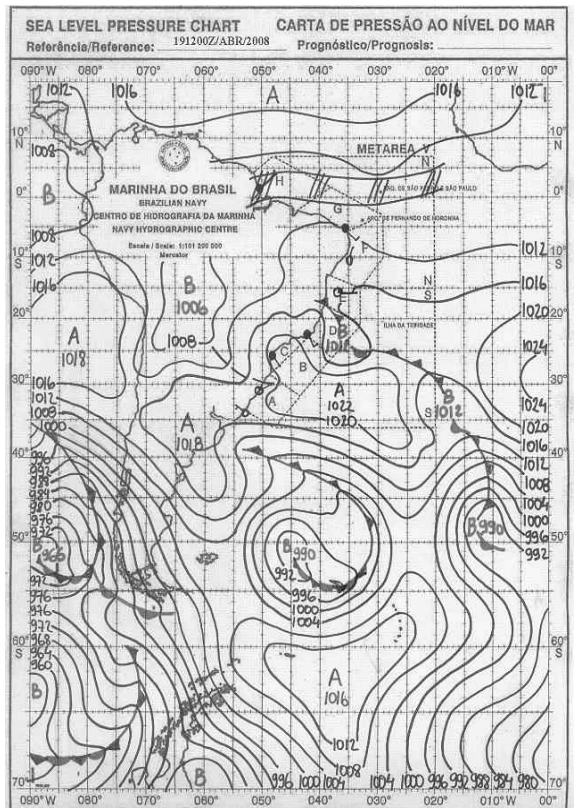

Figura 4 - Carta Sinótica do dia 19 de abril de 2008. - Fonte: Marinha do Brasil, Serviço Meteorológico Marinho

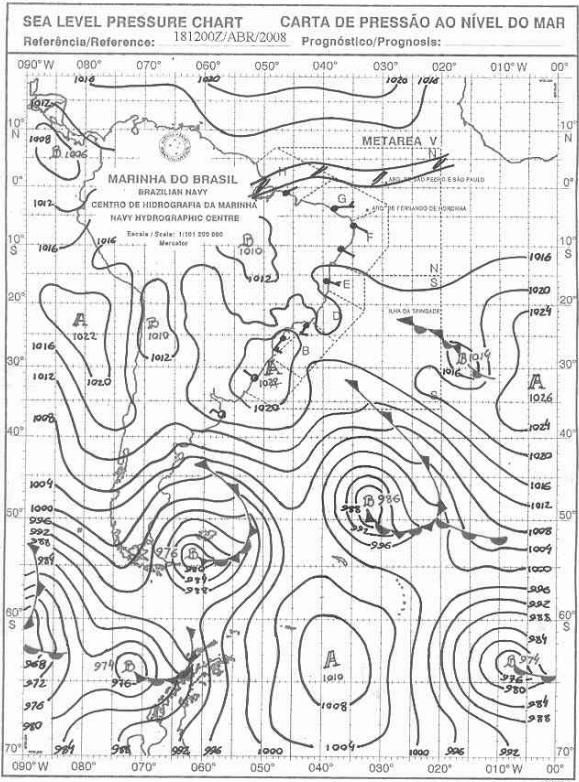

Figura 3 - Carta Sinótica do dia 18 de abril de 2008. - Fonte: Marinha do Brasil, Serviço Meteorológico Marinho

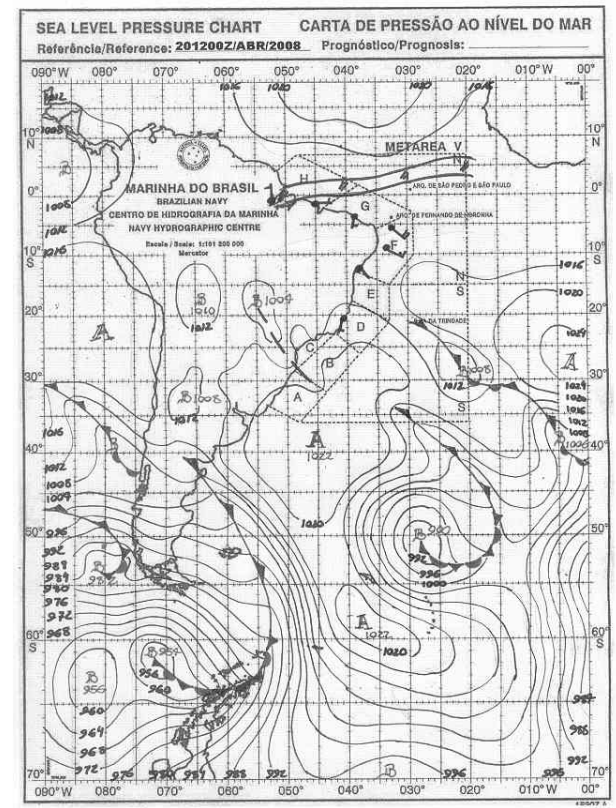

Figura 5 - Carta Sinótica do dia 20 de abril de 2008. - Fonte: Marinha do Brasil, Serviço Meteorológico Marinho 
O artigo tem como base teórico-epistemológica a técnica de análise rítmica de Monteiro $(1969,1973)$ que valoriza os estudos voltados à concepção de ritmo climático, base que está fortemente relacionada à metodologia da pesquisa desse evento climático (Figura 9).

No rol de dados para análise do segmento temporal proposto, o primeiro dia (16 de abril) configurou-se como um dia de influência de uma massa polar que se encontrava em processo de tropicalização na altura do litoral sul brasileiro, com uma intensidade de $1024 \mathrm{mb}$. Desse modo, o predominante vento de leste já atuava sobre Maringá durante a manhã, mas as temperaturas não apresentaram uma alta significativa (temperatura máxima de $21,2^{\circ} \mathrm{C}$ ), devido ao céu estar completamente encoberto com os níveis de umidade relativa, mantendo-se elevados até mesmo na parte da tarde. O quadro então permitiu a ocorrência de chuvas de fraca intensidade no decorrer do dia $(6,4$ $\mathrm{mm}$ no total).

No dia 17 de abril, o que se observa, perante os dados da ECPM, é de que a pressão atmosférica encontrava-se ligeiramente mais elevada do que a apresentada no dia 16, com exceção feita à medição da pressão atmosférica das 18 horas, que se encontrou levemente abaixo do valor do dia anterior, devido à volta da insolação ( 8,2 horas de sol) fazendo com que a temperatura atingisse $27,1^{\circ} \mathrm{C}$ de máxima. O que se deduz com os ventos dos quadrantes sudeste e sudoeste (devido à falta da carta sinótica do dia) é de que houve a manutenção do ar polar, que continuava com o seu processo de tropicalização, e um possível recuo do anticiclone do atlântico sul. O dia encontrava-se parcialmente nublado e, a noite apresentou, por sua vez, céu limpo.

No período diurno do dia 18 de abril, na medição das 12 horas, a direção do vento provinha de nordeste, enquanto que, na noite do mesmo dia, o vento voltou a soprar do quadrante sul devido à influência, primeiramente, do ar mais quente provindo das menores latitudes, e depois com a continuação da atuação da área de anticiclone localizada mais ao sul, com intensidade de 1022 mb. Com relação às temperaturas, estas apresentaram um padrão semelhante ao do dia 17 , chegando a $27,4^{\circ} \mathrm{C}$ de máxima à tarde com consequente decréscimo da UR em $60 \%$. O dia 18 apresentou-se, tal como no dia 17 , parcialmente nublado a encoberto (durante a noite), com um valor de horas de insolação de 6,2. Verifica-se, na carta sinótica, a formação de uma depressão barométrica de $1010 \mathrm{mb}$ no noroeste da Argentina, que viria a contribuir com uma modificação do sistema atmosférico dois dias depois, no dia 20 de abril.

No dia 19 de abril em Maringá, o céu manteve-se encoberto e os ventos, tal como na noite do dia 18, provinham de sudeste na medição das 12 horas e de leste na medição das 18 horas. Como se vê na carta sinótica do dia 19, a área de alta pressão no Atlântico Sul, influente desde o início da análise diária do período em questão, deslocou-se novamente para latitudes menores devido ao avanço de um ciclone extratropical com uma intensidade de 990 mb, explicando a alteração da mudança de direção do vento. A influência do ciclone extratropical realimentou em níveis de umidade a área de anticiclone vizinha, ocasionando a presença do céu encoberto, leve precipitação até às $12 \mathrm{~h}$ em Maringá (3,5 mm), e aumento dos níveis de umidade relativa, nunca abaixo de $75 \%$ no dia. Verificou-se também uma intensificação da área de baixa pressão atmosférica no interior do continente sulamericano, agora se estendendo do noroeste da Argentina até os países andinos do Peru, Bolívia e setor norte do Brasil, com um valor de 1006 mb. Constatou-se, portanto, que a configuração sinótica do dia 19 tornou-se mais instável, a umidade relativa aumentou, 
segundo os dados da própria ECPM, e existiu um reforço de ar quente provindo de latitudes menores do interior do continente sulamericano.

No dia 20, um dia antes do temporal de granizo, o céu manteve-se encoberto na parte da manhã, ficando o dia parcialmente nublado no período da tarde. Desse modo, a temperatura elevou-se rapidamente para $25,5^{\circ} \mathrm{C}$. A mudança do tempo para uma condição de maior estabilidade ocorreu devido ao deslocamento do ciclone extratropical para setores mais longuinquos do Oceano Atlântico, diminuindo a transferência de umidade para a área do anticiclone, agora localizado em sua retaguarda. Entretanto, o fluxo de ventos quentes do interior do continente continuou, representado pelos ventos de norte na parte da tarde. Notou-se também a influência e a repercussão da formação de uma frente fria mais ao sul, somadas à influência da extensa área de alta pressão localizada em todo o litoral sul brasileiro, no período da noite do dia 20 , com os ventos oriundos do sudoeste. O que se analisa é uma alternância entre ventos mais quentes (vindos do norte) e mais frios (provindos da influência do anticiclone), além da manutenção de níveis de UR elevados (menos na parte da tarde com o pico de elevação da temperatura).

\title{
O Dia do Temporal
}

Observa-se na carta sinótica do dia 21 de abril que, devido a incursão hora de ventos de mais quentes, hora de ventos mais frios, os níveis de instabilidade na região aumentaram significativamente. Esse fator comprova a formação de um representativo vórtice ciclônico na altura do litoral sul. Outro fator de relevância para a contribuição da formação de áreas de instabilidade seria o fortalecimento da intensidade da área de alta pressão, agora em 1030 $\mathrm{mb}$, situada entre o ciclone extratropical localizado mais internamente do Oceano Atlântico, e uma nova frente fria ainda na Argentina. Essa conjunção de fatores, aliada ao fluxo de calor do Brasil Central, favoreceu a formação de um ambiente atmosférico altamente instável. Outra característica do dia 21 de abril encontra-se nos níveis de insolação (5,9 horas) e elevados índices de UR, nunca abaixo de $75 \%$. Desse modo, o dia em questão apresentou a sensação de tempo abafado, também devido ao céu não totalmente encoberto, o que permitiu as horas de insolação. O Centro de Previsão do Tempo e Estudos Climáticos também cita a configuração atmosférica regional da seguinte forma na página do seu site (http://www7.cptec.inpe.br/noticias/faces/noticias.jsp?idConsulta $=8487$ \&idQuad $\underline{\text { ros }}=)$ :

\begin{abstract}
"A atualização das $12 z$ do modelo GFS do dia 21/04 indicava umidade elevada tanto em baixos níveis quanto em níveis médios da atmosfera, como podemos observar na figura 2, no painel de umidade e/ou nebulosidade. (...) Podemos observar também ventos intensos em altitude associados com a presença do Jato Subtropical (JST) contornando o Vórtice Ciclônico (VC). Este VC pode ser notado tanto em 500hPa como mostra a corrente de ventos no terceiro painel, quanto em 250hPa. (...) Como conclusão observamos que havia muitas condições para a ocorrência de granizo sobre Maringá. Havia o Vórtice Ciclônico, ar frio em níveis médios da atmosfera e calor e umidade em superfície, tudo indicava muita instabilidade sobre a área."
\end{abstract}




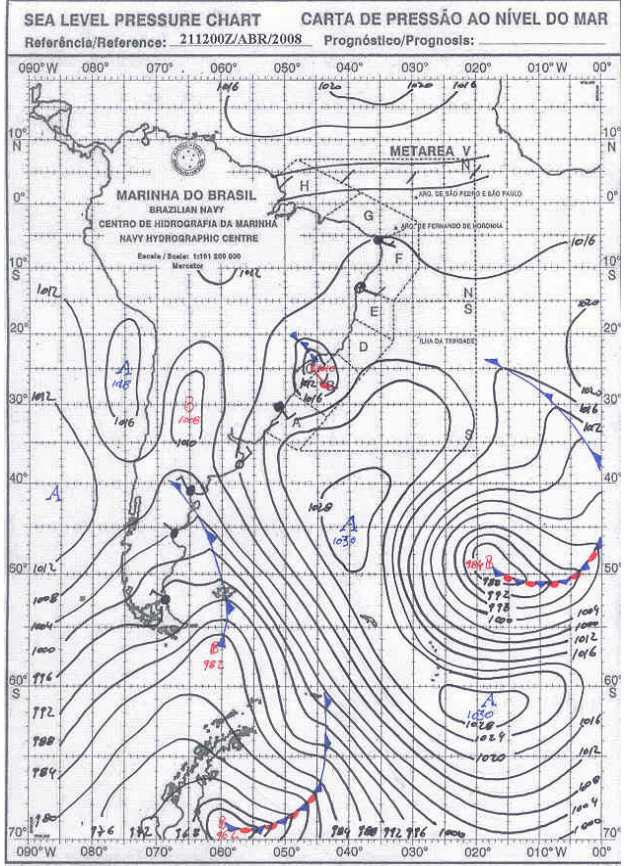

Figura 6 - Carta Sinótica das 09:00h do dia 21 de abril de 2008. Fonte: Marinha do Brasil - Serviço Meteorológico Marinho

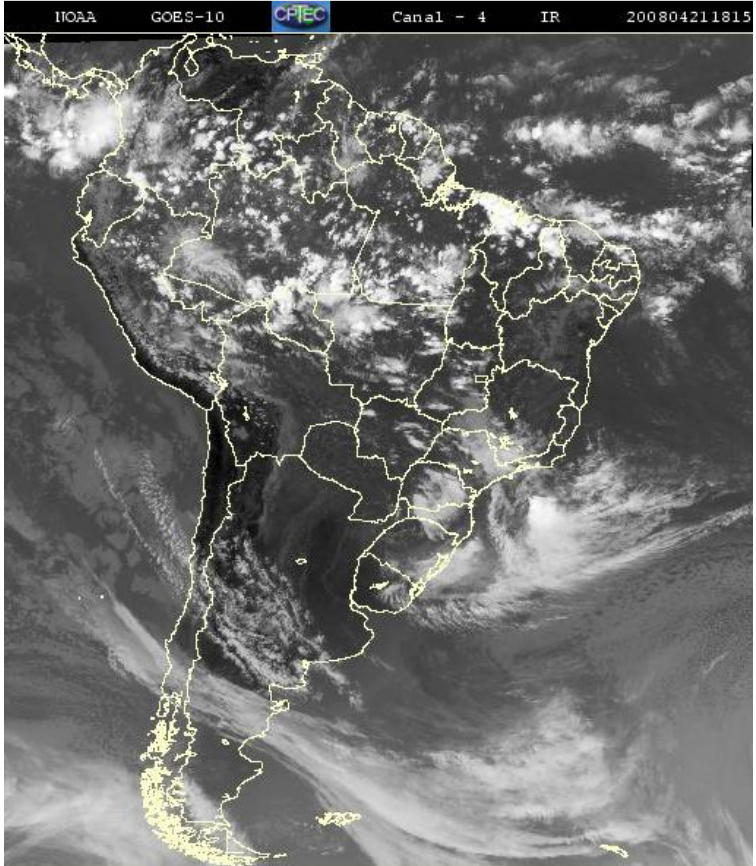

Figura 7 - Imagem de nuvens das 18:15h do dia 21 de abril de 2008. Fonte: Centro de Previsão do Tempo e Estudos Climáticos

Até às 14 horas, a intensidade dos ventos não tinha ultrapassado a marca de $1,0 \mathrm{~m} / \mathrm{s}$. Rapidamente após ao meio-dia começou a se evidenciar a formação de nuvens, e de trovoadas e relâmpagos a partir das 14:30h. Entretanto, as nuvens não se apresentavam com uma coloração tão negra e nem todo o céu apresentava-se, até às $14: 30 \mathrm{~h}$, totalmente encoberto (relato visual do autor). O início da chuva se deu às 14:58 com uma pesada saraiva de granizo que durou até as 15:06, segundo dados da ECPM. Convém destacar que o evento de temporal não começou com uma chuva moderada com, posteriormente, a queda do granizo; ele ocorreu quase imediatamente ao início da chuva. Dois minutos após o início da saraiva, os ventos começaram a soprar do quadrante sudoeste, alcançando as rajadas de 12,0 até $22 \mathrm{~m} / \mathrm{s}(80 \mathrm{~km} / \mathrm{h})$ juntamente com a continuação da precipitação das pedras de gelo. Os ventos perduraram com intensidade significativa por dez minutos, até às 15:10, quatro minutos além do final da saraiva. A primeira precipitação terminou logo após esse período, e os transeuntes foram à rua ver os estragos e as pedras de gelo. Somado ao espanto e ao medo dos moradores, um novo evento de precipitação começou a ocorrer às 15:55 com uma nova queda de granizo, porém com as pedras apresentando um diâmetro menor dos que a da primeira chuva. Todavia, a precipitação de granizo durou mais cinco minutos até às 16:00 horas. A chuva, por sua vez, persistiu por mais vinte minutos, e os relâmpagos e trovoadas estiveram presentes até às 16:40 horas. 


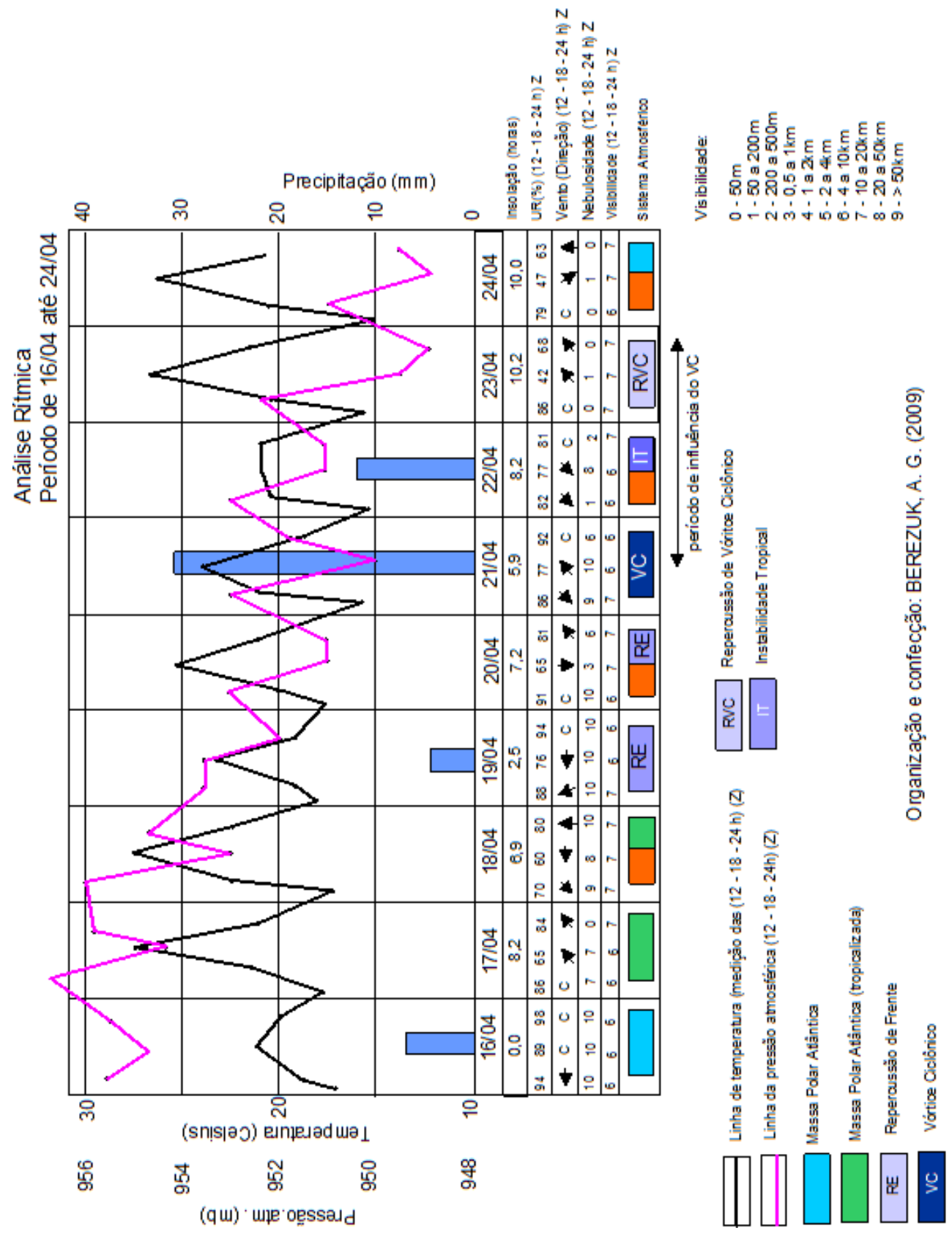

Figura 9 - Gráfico de análise rítmica do período de 16 de abril a 24 de abril de 2008.

Moradores relataram nunca terem visto uma chuva de granizo nessas proporções com tamanha quantidade de pedras de gelo. De fato, ao contrário de cidades do sul brasileiro que possuem já um maior número de casos e históricos referentes às chuvas de granizo, não consta na história do município casos semelhantes a esse. Segundo o diretor da defesa civil vigente na época de ocorrência desse evento extremo, Vagner Musio, cerca de mil e duzentas casas tiveram suas telhas destruídas, sendo necessário que os batalhões de corpo de 160 
bombeiros das cidades de Cianorte, Paranavaí, Londrina e Curitiba enviassem lonas plásticas. Há relatos também da falta de vidro na cidade. Ao todo, dez árvores caíram, foram contadas mais de 300 ocorrências de emergência, e o teto de um shopping center desabou. Por fim, a cidade decretou estado de emergência para agilizar a reparação dos danos.

Os prejuízos também se fizeram presentes na zona rural. Na região, muitas propriedades rurais perderam $100 \%$ de todo o milho que cultivaram, tais como a propriedade rural em Engenheiro Beltrão, próximo de Maringá (Figura 10).

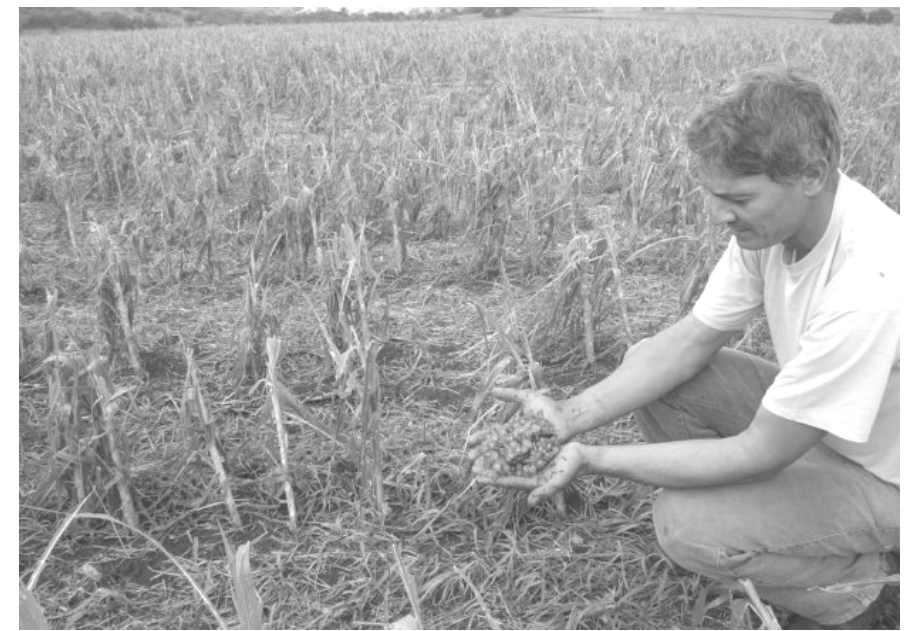

Figura 10 - Estragos na lavoura provocados pela chuva de granizo.

Fonte: Portal da Rede Paranaense de Comunicação, 22 de abril de 2008.

\section{CONSIDERAÇÕES FINAIS}

É próprio da natureza dos eventos climáticos extremos a sua imprevisibilidade, e o evento aqui analisado foi de uma intensidade e destrutibilidade ímpares em todos os 62 anos de história do município de Maringá. O caso em evidência foi tema de muitos debates na mídia regional, ocorrendo principalmente a indagação de que o evento estivesse atrelado à questão do aquecimento global e do efeito estufa excessivo. O fato é de que não será em um estudo de caso de evento extremo que se chegará a alguma conclusão ou a dedução cientificamente comprovada sobre a tendência de exacerbação dos extremos climáticos e seu vínculo com a tendência do aquecimento global, mesmo que haja a forte suspeita de tal relação.

Uma das questões mais preponderante na análise desse estudo de caso é o quanto os núcleos urbanos encontram-se preparados metodologicamente para mitigar impactos provindos de eventos climáticos extremos, e outra seria sobre quais seriam as possibilidades de mudança da própria população com relação ao consumo e fabricação de casas menos vulneráveis a fenômenos como a chuva de granizo. Como exemplo tem-se que, quando se está referindo ao granizo, sabe-se que o uso de telhas tradicionais de barro ou as ecológicas, comprovadamente resistentes a esse tipo de intempérie, é mais adequado que o uso de telhas de amianto. Entretanto, é difícil convencer uma população, ainda 
a mais carente, de a telha de amianto, apesar de ser mais barata, é mais vulnerável, resultando em um maior risco. A questão não fica somente atrelada aos materiais de construção: as populações de menor poder aquisitivo são aquelas que vivem nas encostas dos morros e próximos aos córregos que são as áreas ambientalmente mais vulneráveis (não é o caso de Maringá, que não possui encostas e rede drenagem significativa em sua área urbana).

Eventos como esse, portanto, após a sua ocorrência e impacto psicológico, deveriam estimular e originar o desenvolvimento de projetos de ações técnicocientíficas tais como, por exemplo, a formulação de metodologias que tenham por objetivo medir o grau de vulnerabilidade e sustentabilidade de um núcleo urbano. Além disso, após a formulação de suposta metodologia, deveria-se ser capaz de espacializar, com satisfatório grau de detalhamento, quais seriam as áreas mais ou menos susceptíveis a sofrerem com tais fenômenos, sendo que, em cada nível ou classe de grau de vulnerabilidade ou sustentabilidade, seria pressuposto que a prefeitura da cidade possuísse um rol de procedimentos que visassem a mais rápida e eficiente via de mitigação ou neutralização de prejuízos. A ampla maioria dos municípios brasileiros ainda não possui um sistema de defesa urbana eficiente contra eventos climáticos extremos, estando as pesquisas veiculadas sobre esse tema em seus primeiros passos.

\section{Agradecimentos}

O autor agradece os dados disponibilizados pela Estação Climatológica Principal de Maringá dos dias 16 de abril até 25 de abril de 2008, e a Márcio Eduardo Berezuk e Iris, sem os quais esse artigo não poderia ser realizado.

\section{REFERÊNCIAS}

CENTRO DE PREVISÃO DE TEMPO E ESTUDOS CLIMÁTICOS - Vórtice Ciclônico causa chuva de granizo em Maringá - PR. - 22 de abril de 2008 http://www7.cptec.inpe.br/noticias/faces/noticias.jsp?idConsulta $=8487$ \&idQuadr $\underline{\text { os}}=$ - Acesso em 05 de março de 2009.

Chuva de granizo provoca destruição no Paraná - 21 de abril de 2008 http://g1.globo.com/Noticias/Brasil/0, MUL420213-5598,00.html - Acesso em 05 de março de 2009.

Chuva e granizo causam estragos em Maringá http://www.bemparana.com.br/index.php?n=65469\&t=chuva-e-granizocausam-estragos-em-maringa - Acesso em 05 de março de 2009.

ESTAÇÃO CLIMATOLÓGICA PRINCIPAL DE MARINGÁ - ECPM. Maringá - PR : Dados climatológicos diários dos dias 16 de abril de 2008 até 25 de abril de 2008.

Maringá decreta situação de emergência para agilizar reparação dos danos - 23 de abril de 2008 
http://www.maringa.pr.gov.br/imprensa/noticia.php?id artigo $=6164$ - Acesso em 05 de março de 2009.

MONTEIRO, C. A. F. A frente polar atlântica e as chuvas de inverno na fachada sul-oriental do Brasil: contribuição metodológica à análise rítmica dos tipos de tempo no Brasil. São Paulo : Instituto de Geografia, Universidade de São Paulo, 1969. $68 \mathrm{p}$.

. A dinâmica climática e as chuvas no Estado de São Paulo. São Paulo : Universidade de São Paulo, Instituto de Climatologia, 1973. 129 p.

SERVIÇO METEOROLÓGICO MARINHO, Marinha do Brasil. Carta Sinótica - dos dias 16 de abril de 2008 até 25 de abril de 2008. http://www.mar.mil.br/dhn/chm/meteo/prev/cartas/cartas.htm - Acesso em 02 de março de 2008.

PORTAL RPC, Maringá deve decretar estado de emergência em razão do temporal de granizo, 22 de abril de 2008, Rede Paranaense de Comunicação. http://portal.rpc.com.br/gazetadopovo/vidaecidadania/conteudo.phtml?tl=1\&id =759179\&tit=Maringa-deve-decretar-estado-de-emergencia-em-razao-dotemporal-de-granizo - Acesso em 06 de março de 2008. 
